\title{
Metodologia da problematização: uma possibilidade para o desenvolvimento de competências crítico-reflexivas em contextos curriculares tradicionais
}

\author{
Problematization methodology: a possibility for the development of \\ critical-reflective competences in traditional curricular contexts
}

\section{Metodología de la problematización: una posibilidad para el desarrollo de competencias crítico-reflexivas en contextos curriculares tradicionales}

\author{
CARla Rosane PaZ ARRUda TEO $1{ }^{1}$ \\ Aline TECCHIO BORSOI ${ }^{2}{ }^{2}$ \\ FÁtIMA FERRETTI (1) 1 \\ ${ }^{1}$ Universidade Comunitária da Região de Chapecó, Chapecó, SC, Brasil. \\ ${ }^{2}$ Prefeitura Municipal de Cordilheira Alta, SC, Brasil.
}

\begin{abstract}
RESUMO
O objetivo deste artigo é socializar uma situação de ensino-aprendizagem problematizadora na formação superior em saúde. A situação socializada foi desenvolvida com uma turma de 36 estudantes de um Curso de Nutrição em Santa Catarina, de organização pedagógica tradicional. Foi adotada a metodologia da problematização com o arco de Maguerez. Os estudantes, em disciplina de 40 horas/aula, dividiram-se em grupos, escolhendo uma parcela da realidade para realização das atividades, mediadas por tutoria semanal da professora. Pondera-se que os estudantes desenvolveram a capacidade de leitura de mundo, mobilizaram conhecimentos e articularam teoria e prática. Conclui-se que a metodologia contribuiu para o desenvolvimento de competências crítico-reflexivas, de autonomia e de trabalho em equipe, representando oportunidade de aprendizagem significativa de aplicação viável em contextos curriculares tradicionais.
\end{abstract}

Palavras-chave: Aprendizagem ativa. Educação Superior. Metodologias ativas.

\begin{abstract}
The objective of this article is to socialize a teaching-learning situation based on problematization in higher education in health. The socialized situation was developed with a group of 36 students from a Nutrition Course in Santa Catarina state, with a traditional pedagogical organization. The methodology of the problematization with the Maguerez arch was adopted. The students, in a discipline of 40 class hours, were divided into groups, choosing a portion of reality to carry out the activities, mediated by the teacher's weekly tutoring. We believe the students have developed world-reading skills, mobilized knowledge, and articulated theory and practice. We conclude the methodology contributed to the development of critical-reflexive skills, autonomy, and teamwork, representing a significant learning opportunity of viable application in traditional curricular contexts.
\end{abstract}

Keywords: Activity learning. Higher Education. Activity methods.

\section{RESUMEN}

El objetivo de este artículo es socializar una situación de enseñanza-aprendizaje problematizadora en la formación superior en salud. La situación socializada fue desarrollada con una clase de 36 estudiantes de un Curso de Nutrición en Santa Catarina, con organización pedagógica tradicional. Se adoptó la metodología de la problematización con el arco de Maguerez. Los estudiantes, en disciplina de 40 horas de clase, se dividieron en grupos, eligiendo una parcela de la realidad para realizar las actividades, mediadas por tutoría semanal de la profesora. Se plantea que los estudiantes desarrollaron capacidad de lectura de mundo, movilizaron conocimientos y articularon teoría y práctica. Se concluye que la metodología contribuyó al desarrollo de competencias crítico-reflexivas, de autonomía y de trabajo en equipo, representando oportunidades de aprendizaje significativo de aplicación viable en contextos curriculares tradicionales.

Palabras clave: Aprendizaje activo. Enseñanza Superior. Método activo. 


\section{INTRODUÇÃO}

O conhecimento não tem um sentido em si mesmo: o seu propósito é ser fonte para a compreensão e, por conseguinte, para a intervenção no mundo. Assim, é fundamental que estudantes e educadores mudem a sua visão sobre o conhecimento e a sua relação com os processos de ensinar e apreender. Dessa forma, o verdadeiro sentido do conhecer/aprender reside em uma preparação para compreender o mundo, usufruir do mundo e intervir no mundo, traduzindo, por meio da ação consciente, concepções de homem, sociedade etc. (VASCONCELLOS, 2006).

Nessa perspectiva, não basta ter acesso a informações para que os sujeitos possam participar de modo consciente e integrado da vida em sociedade. As informações são, certamente, a base para essa participação, mas quando memorizadas, retidas por meio de um processo educacional tradicional, propiciam tão somente aos homens serem expectadores do mundo, reproduzindo-o (BERBEL, 2011). Dessa forma, na educação tradicional, restrita ao ato de depositar e à expectativa de produzir, como resposta, uma memorização mecânica do conteúdo narrado, as palavras perdem a sua potência como força transformadora (FREIRE, 2017).

Para superar o nível de reprodução da ação do homem no mundo, um dos principais desafios contemporâneos é o de realizar processos de formação humana integral que favoreçam o desenvolvimento da autonomia individual e coletiva. Nesse contexto, espera-se que a educação contribua para desencadear competências para a leitura das diferentes realidades em sua complexidade, propiciando a construção de redes de mudanças sociais (MITRE et al., 2008).

É nessa direção que apontam os documentos orientadores dos processos de formação de profissionais da área da saúde no Brasil, conhecidos como Diretrizes Curriculares Nacionais (DCN) para os cursos de graduação. As DCN estabelecem uma formação que promova o desenvolvimento de competências e habilidades para o reconhecimento da complexidade do mundo, da transversalidade dos temas relevantes da vida em sociedade, assim como preconizam que as habilidades e competências desenvolvidas no processo de formação devem produzir capacidades de análise, reflexão, crítica, síntese e ética como essenciais para a intervenção qualificada no mundo.

Para dar conta desses desafios, reconhece-se que é preciso superar os processos tradicionais de formação, por incorporação de novas formas de ensinar e aprender. As metodologias ativas surgem, assim, como uma possibilidade de produzir mudanças nessa direção.
Por definição, metodologias ativas são aquelas que colocam os atores do processo (estudantes e educadores) em movimento e interação, nos domínios cognitivo, motor, afetivo, relacional etc. (VASCONCELLOS, 2006), criando uma ambiência favorável para o desenvolvimento de uma motivação intrínseca pelo fortalecimento da percepção de ser a origem da decisão para a ação, o que repercute como sentido de engajamento, pertencimento, responsabilização e comprometimento (BERBEL, 2011).

Essas metodologias têm o potencial de despertar a curiosidade, a busca autônoma, mediada pela ação do educador, de elementos para a teorização em direção da solução de situações-problema, reais ou simuladas. Assim, o estudante é incentivado a superar uma condição passiva (de expectador do mundo) para atingir posturas ativas e, mais do que isso, interativas. No âmbito dessa concepção do ensinar - aprender, o papel do educador (professor, preceptor, tutor etc.) também é outro: não mais de transmissor - na lógica da educação bancária denunciada por Paulo Freire (2017) -, mas de mediador dos processos de aprendizagem, apontando caminhos e possibilidades, desafiando, orientando e questionando, por meio de uma atitude problematizadora (VASCONCELLOS, 2006, MITRE et al., 2008; BERBEL, 2011).

As metodologias ativas favorecem um salto qualitativo nos processos de formação, na medida em que proporcionam a passagem do aprendiz a um novo estágio de engajamento nesse processo. $O$ estudante assume, assim, a condição de protagonista, indo, como propõe Freire (2016), de um momento sincrético, de curiosidade ingênua, para um outro, de consciência crítica, por meio da reflexão, o que requer a curiosidade criativa, indagadora e sempre insatisfeita de um sujeito ativo, que reconhece a realidade como mutável.

Considerando que as metodologias ativas implicam uma mudança de postura de educadores e aprendizes, mais do que apenas a adoção ingênua de estratégias ativas de aprendizagem, sua aplicação não requer, necessariamente, estratégias "dinâmicas". Assim, várias das estratégias que já fazem parte do repertório das práticas dos educadores podem ser aplicadas na perspectiva das metodologias ativas, como estudos de caso, estudo por projetos, produções textuais, diversos tipos de trabalho em grupo, seminários, fóruns, painéis, aprendizagem baseada em problemas, metodologia da problematização com o arco de Maguerez etc. O que importa, nesse caso - reitera-se -, não é tanto a estratégia, mas as posturas de quem aprende e de quem (se) educa.

Nessa direção, é importante considerar que a aproximação com a realidade, concretizada pela metodologia da problematização, responde à necessidade de preparar os futuros profissionais para um aprendizado contínuo, considerando demandas de uma sociedade em 
constante transformação. Particularmente, no caso das profissões da saúde, atende à política de aproximação do ensino com os serviços, garantindo a formação acadêmico-científica, ética e humanística para o desempenho profissional, contextualizado socialmente. A problematização prioriza o desenvolvimento de atividades que permitem ao estudante pensar para além de sua área de formação, possibilitando múltiplas abordagens conceituais e o exercício da interdisciplinaridade (VIEIRA; PINTO, 2015). Nessa perspectiva, o objetivo deste artigo é socializar uma situação de ensinoaprendizagem problematizadora na formação superior em saúde.

\section{Metodologia}

A situação de ensino-aprendizagem foi desenvolvida no segundo semestre do ano de 2016, com uma turma de estudantes do 3 o período de um Curso de Nutrição noturno organizado em um modelo pedagógico de matriz curricular, em uma Universidade no estado de Santa Catarina. O componente curricular, denominado Tópicos em Nutrição III, tinha carga horária de 40 horas/aula e a sua ementa contemplava:

Concepções e princípios metodológicos para o desenvolvimento de práticas em saúde, alimentação e nutrição. Planejamento processual em saúde. Intervenção em saúde, alimentação e nutrição. Vivências participativas em cenários concretos de práticas. Componente articulador do semestre. O conceito-chave dessa fase é intervenção (UNOCHAPECÓ, 2014, p. 68).

Para conduzir o processo de ensino-aprendizagem no componente curricular foi adotada a metodologia da problematização com o arco de Maguerez. Essa metodologia tem origem em um esquema pedagógico proposto por Charles Maguerez com vistas à formação para o trabalho de adultos analfabetos e que foi, posteriormente, adaptado por Bordenave e Pereira (2002) no âmbito da formação de professores. Mais tarde, partindo de uma releitura desses autores, Berbel (1998; 1999; 2012a) conferiu nova consistência teórica e epistemológica ao Arco de Maguerez, pela associação com o conceito de práxis e com a teoria de Paulo Freire, no contexto da educação superior.

Neste trabalho adotou-se a perspectiva de Berbel (1998; 1999; 2012a), a partir da qual a metodologia da problematização com o arco de Maguerez consta de cinco etapas que se desenvolvem a partir da realidade e a ela retornam: a) observação da realidade e definição do problema - momento em que os estudantes, partindo da realidade concreta, observam, registram e identificam um problema relevante que os instigue; b) definição de pontoschave - etapa em que se dá a reflexão acerca dos possíveis determinantes do problema selecionado e a definição dos pontos a estudar; c) teorização - etapa de estudo ou investigação, em que são desenvolvidos os pontoschave definidos por meio da busca de conhecimentos e informações acerca do problema em fontes variadas e sob diferentes aspectos; d) hipóteses de solução - momento em que os estudantes mobilizam seu potencial criativo e reflexivo, planejando ações que possam contribuir para solucionar ou amenizar o problema extraído da realidade; e) aplicação à realidade - consiste na etapa de intervenção, em que são colocadas em prática uma ou mais das hipóteses elaboradas, visando a transformar a realidade observada em algum grau.

Após a discussão e pactuação do plano de ensino do componente curricular com a turma, os 36 estudantes foram solicitados a se reunirem em grupos de seis. A cada grupo foi orientado que escolhesse um contexto para estabelecer contato com a realidade, buscando, por meio da observação, identificar dificuldades, vulnerabilidades, contradições que lhes causassem inquietação, com foco em questões ligadas à alimentação e nutrição. Os estudantes foram, portanto, incentivados a escolherem uma parcela da realidade para se dedicarem à observação, extraindo dessa realidade algo para estudo e intervenção, formulando um problema pertinente, relevante e viável, dando início ao percurso das diferentes etapas do arco.

Todo o processo foi desenvolvido, pelos grupos de estudantes, com tutoria semanal ao longo do componente curricular. Nesse percurso, os grupos produziram registros escritos e fotográficos das diferentes etapas do arco, contendo notas descritivas, reflexivas e, ainda, a sua avaliação, compondo relatórios do processo.

\section{Resultados E Discussão}

Considerando que os estudantes que participaram desta situação de ensino-aprendizagem frequentam um curso noturno, e que vários deles exercem atividades laborais durante o dia, poderiam surgir dificuldades para o desenvolvimento do trabalho com a metodologia da problematização devido a restrições de tempo para as atividades. Assim, todos os grupos foram orientados a escolher um contexto real para estudo que fosse passível de observação no período noturno. Nessa lógica, todos os grupos optaram por realizar a observação da realidade em espaços do campus da Universidade, incluindo restaurante universitário, cantinas, lanchonetes e cafés, usualmente frequentados por professores, estudantes e funcionários técnico-administrativos da Instituição.

Os grupos, nessa fase, utilizaram diferentes recursos, desde a observação passiva até a abordagem informal de 
usuários e gestores dos serviços de alimentação, de forma a ampliarem sua visão e compreensão sobre a realidade. Um grupo (Grupo 2) também adotou a estratégia de visitar um serviço de alimentação similar (um restaurante) em outro contexto, fora do campus, como recurso para explorar semelhanças e diferenças de comportamentos dos usuários em relação ao problema que os instigava ao estudo (no caso, a prática de higienização das mãos antes da refeição).

Durante todo o percurso, os estudantes retornavam semanalmente para tutoria no âmbito do componente curricular, trazendo seus registros, dúvidas, inquietações e proposições, sendo orientados ao seguimento das atividades ligadas ao trabalho, de acordo com as etapas do arco de Maguerez. Ao final da etapa de observação da realidade, os grupos haviam problematizado diversos aspectos acerca dos contextos selecionados, o que resultou na formulação dos problemas para estudo (Quadro 1).

Salienta-se que, de acordo com a metodologia da problematização, os sujeitos são levados a se voltar para a realidade vivida, refletir sobre ela e indagar as razões daquilo que os inquieta e emerge problemático. Ou seja, o ponto de partida é a realidade do sujeito, onde vários problemas são reconhecidos, de maneira que possam ser estudados em contexto de interação. No dizer de Berbel (1999), quando os sujeitos problematizam sua realidade, eles identificam situações-problema concretas, o que permite a construção de novos sentidos e implica um

Quadro 1 - Problemas formulados e pontos-chave definidos pelos grupos de estudantes mediante observação crítico-reflexiva da realidade

\begin{tabular}{|c|c|c|c|}
\hline Grupo & $\begin{array}{l}\text { Síntese dos principais aspectos } \\
\text { observados }\end{array}$ & Problema formulado & Pontos-chave \\
\hline 1 & $\begin{array}{l}\text { Ambiente de refeições barulhento e } \\
\text { agitado; } \\
\text { Significativa utilização de aparelhos } \\
\text { eletrônicos durante a refeição } \\
\text { (telefone celular, tablet); } \\
\text { Refeições 'solitárias'. }\end{array}$ & $\begin{array}{l}\text { Porque as pessoas fazem uso de } \\
\text { aparelhos eletrônicos no momento da } \\
\text { refeição, em prejuízo da sociabilidade? }\end{array}$ & $\begin{array}{l}\text { Influência do uso de tecnologias no } \\
\text { comportamento alimentar e no estilo de } \\
\text { vida. } \\
\text { Consequências para a saúde do uso de } \\
\text { equipamentos eletrônicos durante as } \\
\text { refeições. }\end{array}$ \\
\hline 2 & $\begin{array}{l}\text { No acompanhamento de } 200 \text { usuários } \\
\text { do restaurante, em média, um a cada } \\
\text { dez utilizava o álcool gel disponível } \\
\text { no local e nenhum deslocava-se ao } \\
\text { banheiro para higienizar as mãos com } \\
\text { água e sabão antes da refeição. }\end{array}$ & $\begin{array}{l}\text { Porque pessoas de elevada escolaridade } \\
\text { não higienizam as mãos antes das } \\
\text { refeições? Como sensibilizá-las e } \\
\text { incentivá-las à adoção dessa prática? }\end{array}$ & $\begin{array}{l}\text { Motivos pelos quais os usuários de } \\
\text { serviços de buffet não higienizam as } \\
\text { mãos. } \\
\text { Riscos decorrentes da não higienização } \\
\text { das mãos antes de acessar o buffet. } \\
\text { Importância da prática de higienização } \\
\text { das mãos. } \\
\text { Estratégias e ações educativas para } \\
\text { incentivar esta prática. }\end{array}$ \\
\hline 3 & $\begin{array}{l}\text { Poucas opções de alimentos para } \\
\text { vegetarianos. }\end{array}$ & $\begin{array}{l}\text { Como vegetarianos podem ter uma } \\
\text { alimentação adequada no campus? }\end{array}$ & $\begin{array}{l}\text { Desconhecimento do setor de } \\
\text { refeições sobre o número crescente de } \\
\text { vegetarianos. Desconhecimento sobre a } \\
\text { alimentação vegetariana. } \\
\text { Custos de uma alimentação vegetariana. } \\
\text { Desafios para acessar uma alimentação } \\
\text { adequada com a dieta vegetariana. }\end{array}$ \\
\hline 4 & Elevado consumo de refrigerantes. & $\begin{array}{l}\text { Por que as pessoas continuam tomando } \\
\text { refrigerantes frequentemente mesmo } \\
\text { sabendo de seus malefícios? }\end{array}$ & $\begin{array}{l}\text { Menor praticidade e maior custo de } \\
\text { alimentos/bebidas saudáveis. } \\
\text { Hábito e influência do ambiente (grupo, } \\
\text { mídia, disponibilidade/acesso etc.). }\end{array}$ \\
\hline 5 & $\begin{array}{l}\text { Elevado consumo de açúcar e } \\
\text { adoçantes artificiais (para adoçar } \\
\text { bebidas) e de alimentos doces. }\end{array}$ & $\begin{array}{l}\text { Como contribuir para reduzir o uso de } \\
\text { açúcar e adoçantes artificiais, assim como } \\
\text { o consumo de alimentos doces, pela } \\
\text { comunidade acadêmica? }\end{array}$ & $\begin{array}{l}\text { Implicações do elevado consumo de } \\
\text { açúcar e adoçantes artificiais para a } \\
\text { saúde. } \\
\text { Alternativas ao consumo de açúcar e } \\
\text { adoçantes artificiais. }\end{array}$ \\
\hline 6 & $\begin{array}{l}\text { Elevado consumo de frituras e } \\
\text { refrigerantes. }\end{array}$ & $\begin{array}{l}\text { O que faz com que a comunidade } \\
\text { acadêmica opte por alimentos fritos } \\
\text { e refrigerantes nas refeições? Como } \\
\text { contribuir para a diminuição desse } \\
\text { consumo? }\end{array}$ & $\begin{array}{l}\text { Pouca variedade de alimentos saudáveis } \\
\text { no campus. } \\
\text { Pouco tempo disponível para as refeições } \\
\text { no intervalo das aulas. } \\
\text { Custo dos alimentos mais saudáveis. }\end{array}$ \\
\hline
\end{tabular}

Fonte: Elaboração das autoras (2017). 
real compromisso com esta realidade. Dessa forma, a observação da realidade depende da visão de mundo e das experiências de vida de cada sujeito (BORDENAVE; PEREIRA, 2002), o que explica a diversidade de recursos empregados no processo de observação pelos estudantes, assim como a dos problemas formulados.

Vencida essa etapa, os grupos foram orientados à reflexão coletiva, procurando identificar os possíveis fatores relacionados ao problema formulado, de forma a reconhecer os condicionantes de sua existência, a fim de que fossem definidos os pontos mais relevantes a estudar, ou seja, os pontos-chave. Estes pontos-chave constituem um conjunto de aspectos relacionados ao problema e que precisam ser investigados na busca de soluções. Destacase que esse processo de reflexão deve ser pautado por elementos da literatura, na medida em que se busca compreender como e porque o problema acontece na parcela de realidade observada.

Nesse momento de análise reflexiva, ao entrarem em consenso sobre os aspectos essenciais para a compreensão mais profunda do problema, os estudantes ampliam as suas possibilidades de encontrar maneiras de interferir na realidade. O papel do educador, nessa fase, é o de orientar os estudantes a elaborarem uma síntese, apontando o conjunto de tópicos a serem estudados (VILLARDI; CYRINO; BERBEL, 2015).

Nesse processo explicativo sobre a existência do problema, os grupos elegeram os principais aspectos a serem estudados, a partir de diferentes fontes, concluindo a definição dos pontos-chave (Quadro 1).

A etapa seguinte do trabalho - a da teorização - foi o momento em que os estudantes passaram a buscar, de forma sistematizada, as informações relativas aos pontoschave definidos, tomando como fontes materiais técnicos e marcos legais regulatórios, literatura científica, informações empíricas etc. As informações empíricas foram colhidas por meio de entrevistas e questionários aplicados a gestores e usuários dos diferentes serviços de alimentação observados. Em seu conjunto, as diversas informações colhidas foram tratadas e analisadas, elaborando-se, a partir delas, conclusões, sempre tendo como referência o problema de estudo e a intencionalidade de explicá-lo.

O estudo, nesta etapa, constitui a base para a transformação da realidade. A mediação do educador, portanto, precisa contemplar a orientação para que os estudantes organizem, analisem e avaliem as informações obtidas, na perspectiva de quanto elas podem contribuir para solucionar ou amenizar o problema. Nesse processo, é preciso que os estudantes desenvolvam a capacidade de julgar a validade e a pertinência dessas informações, articulando teoria e prática por meio de discussão e análise, construindo maior consciência acerca do problema e de sua influência sobre o meio social (VILLARDI; CYRINO; BERBEL, 2015).
Salienta-se que, ao refletirem coletivamente sobre o conteúdo sistematizado, os estudantes puderam comparar as suas primeiras representações sobre o problema e os seus conhecimentos prévios - quando discutiram a respeito dos possíveis fatores e determinantes do problema - com as explicações produzidas sobre o problema na fase de teorização. Assim, alguns grupos expressaram a superação e a ampliação de suas ideias iniciais sobre o problema (Grupos 1, 3 e 4), enquanto alguns reconheceram, com surpresa, os equívocos de algumas noções pré-concebidas sobre o objeto de estudo (Grupos 2, 5 e 6).

Essa fase também possibilitou aos estudantes aprofundarem os conhecimentos acerca do problema estudado, estabelecendo uma comparação entre o que se conhecia anteriormente - em uma visão mais do senso comum - e o que se foi construindo, em uma perspectiva mais científica. Esse movimento amplia as possibilidades de resolutividade do problema em estudo. Questões como acesso, custo, tempo, consumo, riscos, hábitos, estilo de vida, tecnologias, ambiente, entre outros pontoschave elencados para estudo, ampliaram o olhar dos estudantes sobre o problema ao provocarem uma reflexão interdisciplinar nos grupos, desvelando uma realidade que poderia ser modificada mediante as intervenções que seriam produzidas.

À vista disso, percebe-se que, inicialmente, os estudantes desenvolveram uma leitura ingênua da realidade (BERBEL, 2012a), porém o seu envolvimento gradativo - no percurso da metodologia da problematização - fez com que a percepção primeira sobre a realidade fosse sendo aprofundada.

Em síntese, nessa etapa, houve um aprofundamento sob diversos ângulos, dos diferentes saberes dos estudantes acerca dos objetos de estudo elencados, processo mediado pela professora e apoiado pela literatura, sendo alcançado um nível ampliado de compreensão sobre a realidade. A esse propósito, Streck (2016, p. 538) afirma que é a partir dos "encontros e cruzamentos de sujeitos que se propõem a conhecer algo" que a complexidade de um objeto é mais bem compreendida.

O aprofundamento e a ampliação do conhecimento, nesse ponto, forneceram elementos aos estudantes para a composição das melhores e mais completas explicações possíveis - naquele momento - para a existência dos problemas formulados, favorecendo o desenvolvimento da quarta etapa da metodologia da problematização: a proposição de hipóteses de solução viáveis.

Nessa etapa, os estudantes foram incentivados a exercitarem a sua criatividade, de forma que aquela realidade, em que havia condições para a existência do problema estudado, pudesse ser transformada em algum grau, mediante as hipóteses propostas. Em outras palavras, as hipóteses elaboradas deveriam representar 
ações que, colocadas em prática, tivessem potencial para produzir mudanças na realidade, solucionando ou, ao menos, minimizando o problema de forma consciente e intencional (BERBEL, 2012a).

Nessa lógica, as hipóteses devem apontar para ações inovadoras naquele contexto, que tenham sido elaboradas a partir de um novo entendimento sobre o problema, mais profundo. Assim, inicialmente, os estudantes foram orientados a registrar todas as possibilidades levantadas, em uma dinâmica de Tempestade de Ideias (ANASTASIOU; ALVES, 2006). Essa dinâmica refere-se à análise do tema proposto com base na prática social já vivenciada e, portanto, utilizando o conhecimento prévio construído, procurando lançar sobre o tema o maior número de ideias possíveis, em um período limitado de tempo, antes de submetê-lo às regras do pensamento lógico.

Para tanto, orientou-se os estudantes a utilizarem essa estratégia pelo seu potencial de mobilizá-los rapidamente para uma vinculação ao tema em estudo (ANASTASIOU; ALVES, 2006). Então, os grupos apontaram hipóteses de solução diversas, abrangendo diferentes esferas de atuação e dimensões do problema, mobilizando intenso potencial reflexivo e criativo, incluindo muitas operações mentais de alto nível, ultrapassando a simples retenção de informações na memória (BERBEL, 2012a).

Nessa direção, o ato de aprender se deu apoiado em um processo que estabeleceu diferentes tipos de relações entre fatos e objetos, promovendo a (re)construção dos saberes, para que o apreendido pudesse ser utilizado em diferentes situações (DEMO, 2004; MITRE et al., 2008).

$\mathrm{Na}$ sequência, os grupos foram incentivados a analisar o corpo de hipóteses levantadas, com base em critérios de adequação, validade e coerência em relação ao problema. Finalmente, recomendou-se a aplicação do critério de governabilidade do grupo para que chegassem a um conjunto pertinente e viável de hipóteses de solução.

Adentrando à quinta etapa da metodologia, a da aplicação à realidade, os grupos foram orientados a selecionarem, minimamente, uma das hipóteses elaboradas para realizarem uma intervenção, isto é, uma ação concreta no mesmo contexto real de onde fora extraído o problema de estudo (Quadro 2).

Quadro 2 - Intervenções realizadas pelos grupos de estudantes, de acordo com as hipóteses de solução formuladas

\begin{tabular}{|c|c|}
\hline Grupo & Aplicação à Realidade (Intervenção) \\
\hline 1 & $\begin{array}{l}\text { Ação educativa realizada por meio de cartazes com orientações para uma vida mais saudável, e pela aplicação de um jogo (Phone Stack) } \\
\text { aos usuários do serviço de alimentação. O jogo consiste em uma pilha de telefones celulares feita por amigos durante a refeição, visando } \\
\text { a favorecer o diálogo e sociabilidade/comensalidade, sendo que o primeiro a retirar o aparelho da pilha se responsabiliza pelo gasto dos } \\
\text { demais. O objetivo da atividade foi mobilizar os usuários para a reflexão sobre a importância e a factibilidade do estímulo à sociabilidade } \\
\text { e os prejuízos do uso de aparelhos eletrônicos durante a refeição. }\end{array}$ \\
\hline 2 & $\begin{array}{l}\text { Ação educativa realizada por meio de placas e cartazes para atrair a atenção dos usuários antes de sua entrada no restaurante, alertando-os } \\
\text { sobre a higienização das mãos. Os cartazes educativos abordaram temas como os riscos associados à não higienização das mãos e } \\
\text { provocações para a mudança desse comportamento, tais como: Oi, você vai usar o álcool gel hoje antes de se servir?, Sabia que usando o } \\
\text { álcool gel você previne doenças transmitidas por alimentos? Você sabe quantas bactérias habitam nas suas mãos agora? } \\
\text { Intervenção com gestores do restaurante, a fim de adequar o layout de forma a favorecer aos usuários a iniciativa de higienização das } \\
\text { mãos. }\end{array}$ \\
\hline 3 & $\begin{array}{l}\text { Ação educativa realizada por meio de exposição (com degustação) aos usuários dos serviços de alimentação do campus de opções de } \\
\text { marmitas vegetarianas que podem ser preparadas e adequadamente armazenadas para serem levadas à Universidade, como alternativa } \\
\text { de alimentação saudável/nutritiva e com baixo custo. A exposição foi realizada ao ar livre, apresentando-se, também, um pôster com a } \\
\text { pirâmide alimentar vegetariana, a fim de exemplificar preparações e fornecer informações básicas sobre o vegetarianismo. Foram, ainda, } \\
\text { elaborados e distribuídos folhetos informativos, contendo as receitas preparadas/degustadas. } \\
\text { Intervenção direcionada aos gestores e funcionários dos serviços de alimentação do campus, distribuindo-se folhetos informativos sobre a } \\
\text { alimentação vegetariana e apresentando algumas receitas destinadas a seus adeptos, como opções para serem comercializadas nesses locais. }\end{array}$ \\
\hline 4 & $\begin{array}{l}\text { Ação educativa com objetivo de conscientizar sobre os malefícios à saúde do consumo regular de refrigerantes. Foram utilizados } \\
\text { cartazes com informações sobre os ingredientes contidos em refrigerantes e os malefícios associados, além de incentivo à substituição } \\
\text { por sucos naturais de fruta e água. Também foram utilizadas duas latas de refrigerante (de cola e de laranja), ampolas contendo o teor } \\
\text { seguro de açúcar e de sódio para consumo diário, ampolas com os teores correspondentes de açúcar e sódio dos dois tipos de refrigerante } \\
\text { apresentados, uma garrafa de água mineral, um copo de suco natural de laranja. Foram, ainda, distribuídos folhetos informativos sobre } \\
\text { esses temas. A escolha por cartazes e ampolas se justificou pelo fato de que os usuários destes serviços de alimentação, normalmente, } \\
\text { têm um intervalo curto para a refeição, passando apressadamente nesses locais. Assim, o uso de materiais com forte apelo visual poderia } \\
\text { chamar sua atenção, comunicando rapidamente as informações pretendidas. }\end{array}$ \\
\hline 5 & $\begin{array}{l}\text { Ação educativa focada em demonstrar o alto consumo de açúcar na atualidade. Foram utilizados cartazes, folders, ampolas, amostras de } \\
\text { açúcar e degustação de doces com teor reduzido de açúcar. Como incentivo ao consumo de alimentos com menor quantidade de açúcar } \\
\text { adicionado e, ao mesmo tempo saborosos, foram oferecidos para degustação doces de amendoim, preparados com } 50 \% \text { de cacau, açúcar } \\
\text { mascavo, cravo e canela. }\end{array}$ \\
\hline 6 & $\begin{array}{l}\text { Ação educativa realizada por meio de um painel com a pirâmide alimentar e de exposição de diversas opções de sanduíches naturais (em } \\
\text { versões preparadas com pão integral e branco), suco de laranja natural, além de ampolas que davam o suporte para esclarecer a quantidade } \\
\text { de açúcar, sal e outros condimentos presentes nos alimentos industrializados. }\end{array}$ \\
\hline
\end{tabular}

Fonte: Elaboração das autoras (2017). 
De acordo com Villardi, Cyrino e Berbel (2015, p. 48),

Nessa etapa, devem ser analisadas e escolhidas as propostas de soluções mais viáveis, que poderão ser postas em prática e ajudarão a superar o problema no todo ou em parte, contribuindo para a transformação da realidade investigada. É o momento de planejamento e de execução, de desenvolvimento de um compromisso social, profissional e político.

Ao aplicarem ações concretas, derivadas do aprofundamento do conhecimento sobre o problema, os estudantes assumiram um compromisso com a realidade. Assim, materializa-se um retorno do estudo à realidade investigada, na qual se intervém de forma concreta, utilizando-se de uma ou mais das hipóteses de solução delineadas. $\mathrm{O}$ retorno à realidade significa uma prática consciente, informada e intencionalmente transformadora (BERBEL, 2012a).

Em síntese, o processo de ensino-aprendizagem com a metodologia da problematização é um percurso em que se extrai um problema da realidade e realiza-se um estudo sobre ele, refletindo-se sobre suas causas e possíveis soluções. Por fim, retorna-se à mesma realidade, por meio de intervenções que possam transformá-la em alguma medida.

É importante salientar que a metodologia da problematização não é um mero exercício intelectual, mas um percurso que estimula o estudante a ir além disso, assumindo compromisso social e político com a realidade, o que o conduz a avançar em sua postura dialética de ação-reflexão-ação, tendo a realidade social como ponto de partida e de chegada (BERBEL, 2012b).

Cabe, ainda, ponderar que, no desenvolvimento desta situação de ensino-aprendizagem, foram observadas algumas limitações. Constatou-se, nesse sentido, que nem todos os grupos realizaram o percurso da metodologia com o mesmo comprometimento, tampouco apresentaram o mesmo nível de avanço em termos do aprofundamento e ampliação do conhecimento, ou de desenvolvimento de um efetivo compromisso com a realidade. Assim, houve grupos que desenvolveram intervenções com maior potencial resolutivo, abrangendo tanto o público usuário dos serviços quanto seus gestores e funcionários (Grupos 2 e 3). Diferentemente, os demais grupos realizaram intervenções menos elaboradas, dirigidas apenas aos usuários, em uma lógica um tanto quanto prescritiva ainda.

Contudo, esse cenário não é de todo inesperado, visto que, conforme já afirmado, cada estudante traz consigo a sua própria visão de mundo (BORDENAVE; PEREIRA, 2002), o seu conhecimento prévio (FREIRE, 2016). Além disso, cada um, nessa perspectiva, deixa-se (ou não) tocar de modos bastante peculiares pela realidade. Assim é que Larrosa (2011, p. 22) afirma:
A experiência não está do lado da ação, ou da prática, ou da técnica, mas do lado da paixão. Por isso a experiência é atenção, escuta, abertura, disponibilidade, sensibilidade, vulnerabilidade, ex/ posição. Isso não quer dizer, no entanto, que a ação, ou a prática, não possam ser lugares de experiência. Às vezes, na ação, ou na prática, algo me passa. Mas esse algo que me passa não tem a ver com a lógica da ação, ou da prática, mas, justamente, com a suspensão dessa lógica, com sua interrupção.

A despeito dessas limitações, alguns grupos evidenciaram avanços expressivos no processo, chegando a um nível elaborado de reflexão e crítica sobre a intervenção realizada na etapa de aplicação à realidade, como ilustra o registro apresentado a seguir:

Percebemos que a intervenção com foco na orientação para vegetarianos, sobre como ter uma alimentação saudável e a dificuldade da adequação da dieta, deveria ser realizada de outra forma, não aberta ao público em geral, mas reservada para atingir esse público específico. Uma alternativa poderia ser a divulgação prévia da atividade, para atrair a atenção dos mesmos para o local (Grupo 3, informação verbal). ${ }^{1}$

Houve também registros de autocrítica, indicando um processo avançado de reflexão também na etapa de definição de pontos-chave:

Quando nos reunimos para discutir sobre o problema que formulamos, concluímos a segunda etapa, de definição dos pontos-chave de estudo, com um grande questionamento a respeito do papel de cada um na promoção da saúde: como posso esperar que outros façam o que nem eu mesmo faço? (Grupo 2, informação verbal). ${ }^{2}$

Neste ponto também se evidencia o processo de conscientização dos estudantes, por meio do qual, conforme seguiam desvelando o objeto inicialmente percebido, foram alcançando uma percepção mais crítica, informada, analisada e refletida. De acordo com Berbel (2012a), a conscientização se vai construindo nesse movimento, quando superamos a primeira percepção e aprofundamos o conhecimento de maneira crítica e reflexiva.

Cabe destacar, também, que os grupos estabeleceram conexões entre a atividade desenvolvida com a metodologia da problematização e os conteúdos abordados em outras disciplinas ao longo do curso, especialmente na etapa da teorização:

\footnotetext{
Depoimento concedido às autoras em 26 de novembro de 2016.

2 Depoimento concedido às autoras em 19 de novembro de 2016.
} 
Foi importante perceber que já tínhamos vários conhecimentos sobre isso [a higienização de mãos] e que, agora, nessa situação, foram úteis. Retomamos nossos materiais das disciplinas de Estudo dos Alimentos II, de Higiene de Alimentos.... É gratificante ver que realmente estamos aprendendo... (Grupo 2, informação verbal). ${ }^{3}$

Essa observação reitera a ideia de que o estudante traz consigo saberes advindos de outras fontes e, ao se aproximar da realidade, ao ser confrontado com as informações dessa realidade, consegue problematizá-la, articulando os conhecimentos que já possui com aqueles com que se depara ao estar frente à realidade (VILLARDI; CYRINO; BERBEL, 2015).

Os estudantes referiram, ainda, a relevância de que sejam superadas, em se tratando de educação em saúde, posturas prescritivas, valorizando-se a capacidade de leitura da realidade e de aprofundamento do conhecimento científico, como evidenciado no seguinte registro:

A partir dos resultados, fica evidente a necessidade de conhecimento sobre a realidade e sobre o tema/ problema, a fim de direcionar o planejamento e a realização de ações, usando estratégias pedagógicas adequadas, capazes de contribuir para a melhoria da realidade observada (Grupo 1, informação verbal). ${ }^{4}$

Há que se pontuar, também, que os estudantes reconheceram a contribuição das atividades com a metodologia da problematização para sua formação:

A metodologia adotada na disciplina para a realização do trabalho foi muito interessante. Permitiu-nos utilizar nossa bagagem de conhecimento já adquirida e aplicá-la no contexto da prática. Pudemos atuar de modo crítico, a partir da observação da realidade, para encontrar possíveis vulnerabilidades e problemas existentes. Passamos, então, a buscar mais conhecimento sobre o tema abordado, e a usar de criatividade para poder buscar alternativas de enfrentamento para o problema a ser trabalhado. A metodologia da problematização nos possibilitou relacionar teoria e prática (Grupo 3, informação verbal). ${ }^{5}$

E ressaltaram:

Foi de suma importância esse contato mais direto com as pessoas, tanto para nós (futuros profissionais) quanto para o público, leigo nesse assunto, sendo uma experiência muito gratificante, pois conseguimos trabalhar na prática com o que aprendemos na teoria. Além disso, nos sentimos muito acolhidos pelas pessoas, que demostraram interesse e interagiram

\footnotetext{
3 Depoimento concedido às autoras em 19 de novembro de 2016.

4 Depoimento concedido às autoras em 12 de novembro de 2016.

5 Depoimento concedido às autoras em 26 de novembro de 2016.
}

conosco, pois a intervenção foi muito bem aceita por quem participou e contribuiu (Grupo 4, informação verbal). ${ }^{6}$

Concluindo que:

O grupo, ao final da atividade, avalia como positiva, por termos vivenciado momentos tão marcantes quanto esses. Foi um contato muito rico com o público, que fortaleceu a nossa visão sobre as vulnerabilidades das pessoas quando se trata de hábitos alimentares e de como modificá-los. O grupo agiu, de fato, como uma equipe, dividindo de forma adequada tarefas e responsabilidades, e cada um cumpriu com seus compromissos e respeitou o grupo. Analisando todos os aspectos trabalhados durante a intervenção, o grupo, em consenso, acredita que foi uma experiência importante para cada um, tanto pela visão de acadêmico do Curso, nesse momento, como pela questão de, no futuro, após a formação, como profissionais (Grupo 5, informação verbal). ${ }^{7}$

Percepção semelhante foi encontrada no estudo realizado por Rego e Rodrigues (2015) com 26 estudantes da pós-graduação em que se avaliou sua opinião sobre a aplicação da metodologia da problematização com o Arco de Maguerez no desenvolvimento da disciplina de Didática Aplicada ao Ensino Superior em Saúde. Segundo os autores, os estudantes consideraram que foram suficientemente encorajados a desenvolverem um pensamento crítico sobre as situações abordadas, avaliando que a metodologia da problematização representa um modelo de aprendizagem para o desenvolvimento profissional contínuo, em contato com a realidade social.

Considera-se que, no presente estudo, os estudantes também avaliaram positivamente o trabalho com a metodologia da problematização, com destaque, segundo eles, para a possibilidade de articulação entre teoria e prática e para a mobilização de conhecimentos trabalhados em outros momentos do curso.

Isso corrobora a ideia de que, quando realizadas e construídas de modo cuidadoso e com intencionalidade, estratégias de ensino problematizadoras - como a metodologia da problematização com o Arco de Maguerez - podem contribuir de maneira significativa para uma formação de qualidade e comprometida com a realidade (VILLARDI; CYRINO; BERBEL, 2015).

Importante considerar, aqui, que esse processo também constrói uma dinâmica de interações que se estabelece entre estudantes e professores, entre eles e a realidade e, ainda, entre eles e o conhecimento, em um processo irreversível. Salienta-se que o professor também

\footnotetext{
${ }^{6}$ Depoimento concedido às autoras em 3 de dezembro de 2016.

7 Depoimento concedido às autoras em 03 de dezembro de 2016.
} 
é afetado, também sofre transformações, pois a realidade é viva, atraente, multifacetada e, em geral, contraditória, o que a faz provocativa e infinitamente potencializadora de novas indagações, reflexões e conhecimentos (BERBEL, 1995).

Dessa forma, a metodologia da problematização, enquanto metodologia ativa, se caracteriza como uma experiência profícua na formação dos profissionais da área da saúde, na medida em que tanto docentes quanto estudantes passam a refletir criticamente sobre os sentidos do ensinar e aprender. Além disso, a metodologia promove a aproximação dos estudantes com a realidade de saúde e adensamento do conhecimento acerca dos serviços em que se inserem, viabilizando processos de mudanças no campo de atuação. Ainda, possibilita a construção de espaços de diálogo, troca de informações, relação de cooperação e respeito entre os envolvidos (BALLARIN et al., 2013), aspectos que devem ser potencializados ao longo de todo o processo de formação profissional.

\section{CONSIDERAÇÕES FINAIS}

Diante do objetivo anunciado, pondera-se que, por meio da metodologia da problematização, os estudantes exercitaram a observação da realidade, desenvolvendo sua capacidade de leitura de mundo. Também teorizaram, mobilizando conhecimentos disciplinares em busca da resolução de um problema real, em um movimento interdisciplinar. $\mathrm{Na}$ intervenção, articularam teoria e prática, embora em diferentes níveis de consciência da práxis, valorizando o contato com a realidade social e reconhecendo a contribuição deste trabalho para a sua formação.

A partir da perspectiva da mediação, reconhece-se, aqui, que a experiência com a metodologia da problematização contribuiu para o desenvolvimento, pelos estudantes, de competências crítico-reflexivas, de autonomia e de trabalho em equipe.

Finalmente, argumenta-se que essa metodologia representa uma oportunidade de aprendizagem significativa, no contato e no confronto direto com a realidade, onde a ação humana ocorre efetivamente. Apesar das limitações discutidas, propõe-se que é viável a aplicação da metodologia da problematização em contextos de formação mais tradicional (como o curso em tela, organizado sob a forma de matriz curricular) e de restrição de tempo para atividades de contraturno (como, nesse caso, o curso noturno). No entanto, resta o desafio de que situações de ensino-aprendizagem problematizadoras não sejam pontuais, frente às dificuldades apontadas.

Nesse sentido, aponta-se como perspectiva, a partir desse estudo, para um planejamento coletivo do corpo docente, que considere a utilização da metodologia da problematização dentro das limitações de cada realidade.
Em cursos com limitações semelhantes às aqui relatadas, em termos de sua estrutura e organização pedagógica, poderiam ser criadas situações de aprendizagem envolvendo vários (ou todos) componentes curriculares de um mesmo período, de forma que os estudantes pudessem vivenciar essa estratégia, ao longo de sua formação, pelo menos uma vez a cada período.

A esse propósito, argumenta-se que as instituições formadoras de profissionais de saúde devem empenhar-se para promover mudanças nas práticas pedagógicas e que, nessa direção, o exercício continuado e permanente de metodologias problematizadoras pode contribuir efetivamente para a formação de profissionais com perfil crítico e reflexivo, mais preparados para o atendimento das demandas de saúde da população em contextos reais, qualificando a assistência desenvolvida nos serviços.

\section{REFERÊNCIAS}

ANASTASiOU, L. G. C.; ALVES, L. P. (org.). Processos de ensinagem na universidade: pressupostos para as estratégias de trabalho em aula. 6. ed. Joinville: UNIVILLE, 2006.

BALLARINA, M. L. G. S. et al. Metodologia da problematização no contexto das disciplinas práticas terapêuticas supervisionadas. Cadernos de Terapia Ocupacional, São Carlos, v. 21, n. 3, p. 609-616, 2013. https://doi.org/10.4322/cto.2013.063

BERBEL, N. A. N. A metodologia da problematização com o Arco de Maguerez: uma reflexão teórico-epistemológica. Londrina: EDUEL, 2012a. https://doi.org/10.26694/reufpi. v4i3.4173

BERBEL, N. A. N. A metodologia da problematização em três versões no contexto da didática e da formação de professores. Revista Diálogo Educacional, Curitiba, v. 12, n. 35, p. 101-18, 2012b. https://doi.org/10.7213/dialogo. educ. 5904

BERBEL, N. A. N. A problematização e a aprendizagem baseada em problemas: diferentes termos ou diferentes caminhos? Interface: Comunicação, Saúde, Educação, Botucatu, v. 2, n. 2, p. 139-54, 1998. https://doi.org/10.1590/ s1414-32831998000100008

BERBEL, N. A. N. As metodologias ativas e a promoção da autonomia de estudantes. Semina: Ciências Sociais e Humanas, Londrina, v. 32, n. 1, p. 25-40, 2011. https://doi. org/10.5433/1679-0383.2011v32n1p25

BERBEL, N. A. N. Metodologia da problematização: fundamentos e aplicações. Londrina: EDUEL, 1999.

BERBEL, N. A. N. Metodologia da problematização: uma alternativa metodológica apropriada ao ensino superior. Semina: Ciências Sociais e Humanas, Londrina, v. 16, n. 2, p. 9-19, 1995. https://doi.org/10.5433/16790383.1995v16n3p09 
BORDENAVE, J. D.; PEREIRA, A. M. Estratégias de ensino aprendizagem. 25. ed. Petrópolis: Vozes, 2002.

DEMO, P. Professor do futuro e reconstrução do conhecimento. Petrópolis: Vozes, 2004.

FREIRE, P. Pedagogia da autonomia: saberes necessários à prática educativa. 54. ed. São Paulo: Paz e Terra, 2016. https:// doi.org/10.9771/2317-1219rf.v13i13.3221

FREIRE, P. Pedagogia do oprimido. 63. ed. São Paulo: Paz e Terra, 2017.

LARROSA, J. Experiência e alteridade em educação. Revista Reflexão e Ação, Santa Cruz do Sul, v. 19, n. 2, p. 4-27, 2011. https://doi.org/10.17058/rea.v19i2.2444

MITRE, S. M. et al. Metodologias ativas de ensinoaprendizagem na formação profissional em saúde: debates atuais. Ciência \& Saúde Coletiva, Rio de Janeiro, v. 13, supl. 2, p. 2133-2144, 2008. https://doi.org/10.1590/s141381232008000900018

UNOCHAPECÓ. Síntese do projeto pedagógico do curso de graduação em Nutrição (bacharelado). Chapecó: UNOCHAPECÓ, 2014. Disponível em: https://www. unochapeco.edu.br/static/data/portal/sites/ppc/57.pdf. Acesso em: 18 ago. 2017. https://doi.org/10.23925/18093876.2017v15i1p200-220

REGO, H. M. C.; RODRIGUES, J. R. Metodologia da problematização com o Arco de Maguerez: um método complementar para a educação em odontologia. Brazilian Dental Science, São José dos Campos, v. 18, n. 1, p. 34-43, 2015.

STRECK, D. R. Metodologias participativas de pesquisa e educação popular: reflexões sobre critérios de qualidade. Interface: Comunicação, Saúde, Educação, Botucatu, v. 20, n. 58, p. 537-547, 2016. https://doi.org/10.1590/180757622015.0443

VASCONCELLOS, C. S. Avaliação: concepção dialéticalibertadora do processo de avaliação escolar. 16. ed. São Paulo: Libertad, 2006.

VIEIRA, M. N. C. M.; PANÚNCIO-PINTO, M. P. A Metodologia da Problematização (MP) como estratégia de integração ensino-serviço em cursos de graduação na área da saúde. Medicina, Ribeirão Preto, v. 48, n. 3, p. 241-248, 2015. https://doi.org/10.11606/issn.2176-7262.v48i3p241-248

VILLARDI, M. L.; CYRINO, E. G.; BERBEL, N. A. N. A problematização em educação em saúde: percepções dos professores tutores e alunos. São Paulo: UNESP, 2015. https://doi.org/10.7476/9788579836626
Endereço para correspondência:

Carla Rosane Paz Arruda Teo

Servidão Anjo da Guarda, 295D - Efapi

89809-900, Chapecó, SC, Brasil

Autoras:

Carla Rosane Paz Arruda Teo

Doutora em Ciências de Alimentos pela Universidade Estadual de Londrina (UEL).

Docente do Curso de Nutrição e do Programa de Pós-Graduação em Ciências da

Saúde da Universidade Comunitária da Região de Chapecó (Unochapecó),

Chapecó, SC, Brasil.

Orcid: http://orcid.org/0000-0002-1534-6261

E-mail: carlateo@unochapeco.edu.br

Aline Tecchio Borsoi

Mestre em Ciências da Saúde pela Universidade Comunitária da Região de Chapecó (Unochapecó). Nutricionista da Secretaria Municipal de Educação de Cordilheira Alta, SC, Brasil.

Orcid: https://orcid.org/0000-0001-7853-9696

E-mail: aline.borsoi@gmail.com

Endereço: Rua Celso Tozzo, 27 - Centro

89819-000, Cordilheira Alta, SC, Brasil

FÁtIMA FERRETTI

Doutora em Saúde Coletiva pela Universidade Federal de São Paulo (UNIFESP).

Docente do Curso de Fisioterapia e do Programa de Pós-Graduação em Ciências da Saúde da Universidade Comunitária da Região de Chapecó (Unochapecó).

Orcid: https://orcid.org/0000-0002-0326-2984

E-mail: ferrettifisio@yahoo.com.br

Endereço: Servidão Anjo da Guarda, 295-D - Efapi

89809-900, Chapecó, SC, Brasil 